$$
\text { "geda" — 2008/8/1 - 11:20 — page } 1 \text { - \#1 }
$$

\title{
Various systems in a single mathematical model
}

\author{
GÁBor GEDA
}

Abstract. Our aim is to study differential equations and systems described by them which have great historical importance and are considered to be fundamental on different levels of education.

Due to their simplicity these are suitable for those who deal with this topic and want to gain useful experience in this field.

Furthermore, our aim is to give these equations a general form which facilitates the studying of the different models by computer even for an individual programmer. At the same time it facilitates the use of different mathematical auxiliary-programmes.

By giving the equations this way we get a chance of studying the relations between the individual systems.

Key words and phrases: nonlinear differential equation system, growth model, combat model, prey-predator model, oscillation.

ZDM Subject Classification: I70, M50, M60, R90.

\section{Introduction}

The different disciplines developed from each other during their historical development.

However, during the $20^{\text {th }}$ century such correlations have been discovered between the achievements of the different disciplines which vanished the strict borders between them.

This phenomenon led to a system-based approach which generalized the description of the different phenomena by using the techniques of mathematics.

Copyright (C) 2008 by University of Debrecen 


$$
\text { "geda" — 2008/8/1 — 11:20 — page } 2 \text { — \#2 }
$$

The differential equations proved to be a useful mathematical tool of the systemtheory. We think it is appropriate to study those possibilities which provide way for approaching phenomena on the basis of system-theory by using certain tools of computer technology.

To achieve this aim, we would like to give a system of non-linear ordinary differential equations with constant-coefficients, which depends on the choice of the coefficients and initial conditions, may be suitable for describing simple exponential growth, periodical phenomenon and any other changes which may have importance in terms of education.

Our aim is to study some famous models which can be described by ordinary differential equations (ODE). Various sorts of phenomenon are known in different fields of science (chemistry, physics, biology, structure of material, ecology and so on), which can be described in a similar way. Maybe the most famous non-linear system is the Lotka-Volterra one. Though it was proposed to describe interaction of two populations (predator-prey), in spite of this, it has been used and later it was applied in other fields as well (e.g., in the field of Chemistry). It shows that the different phenomena can be described in a similar way by the tools of mathematics. Although it is one of the simplest non-linear systems, still it can help to understand other realistic ones.

\section{Mathematical Background}

First, we consider the differential equations

$$
\begin{aligned}
& \dot{X}_{1}(t)=\left(b_{1}-a_{11} X_{1}(t)-a_{12} X_{2}(t)\right) X_{1}(t)+c_{1} X_{2}(t)+e_{1}, \\
& \dot{X}_{2}(t)=\left(b_{2}-a_{21} X_{1}(t)-a_{22} X_{2}(t)\right) X_{2}(t)+c_{2} X_{1}(t)+e_{2}
\end{aligned}
$$

(where $a_{11}, a_{12}, b_{1}, c_{1}, e_{1}, a_{21}, a_{22}, b_{2}, c_{2}, e_{2}$ are real constants and $X_{1}(t), X_{2}(t)$ are real functions). Afterwards we study the conditions under which they are equivalent to certain well-known models. Regarding the limits of this paper, we study only those cases which do not need special background knowledge.

\subsection{Exponential growing (Malthusian Model)}

One of the first researchers of this theory was an Anglican professor of history at Cambridge University in England, Thomas Malthus (1766-1834) who studied the population dynamics and proposed a differential equation to describe it. The 
basic idea of his model based on the following fact: the more people live in a given community, the more babies they will have. According to Malthus, the rate at which a population grows is directly proportional to its current size

$$
\dot{p}(t)=k p(t) .
$$

Nowadays, over 150 years later it seems fairly obvious, but his idea was a ground-breaking concept when he first published it. (Here $p(t)$ represents the population's size at time $t$ and $k$ is the difference of the rates of birth and death. If $k>0$, we have a positive rate of change, population increases; whereas if $k<0$, then we speak about a negative rate of change, population decreases (Figure 1).)
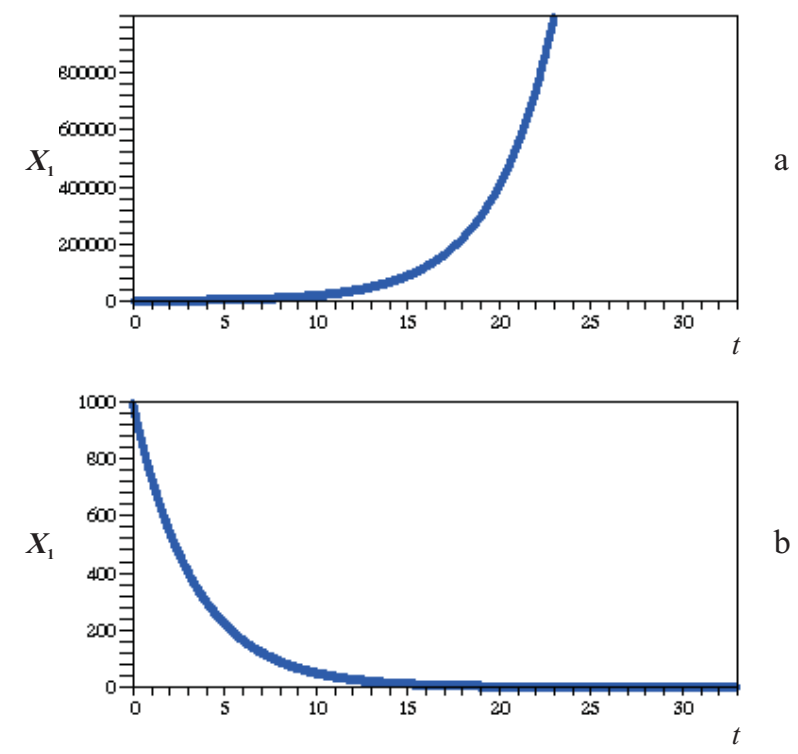

Figure 1. A typical curve of exponential growth. Case a: $b_{1}=+0.3$; $X_{1}(0)=10000 ; X_{2}(0)=0$. Case b: $b_{1}=-0.3 ; X_{1}(0)=10000 ;$ $X_{2}(0)=0$.

Replacing relevant coefficients into (1), choosing suitable initial values, we can transform our model

$$
\dot{X}_{1}(t)=b_{1} X_{1}(t)
$$

in a similar form to Malthusian one, where

$$
\begin{aligned}
& b_{1}>0 ; \quad a_{11}=0 ; \quad a_{12}=0 ; \quad c_{1}=0 ; \quad e_{1}=0 ; \\
& b_{2} \in \mathbb{R} ; \quad a_{21} \in \mathbb{R} ; \quad a_{22} \in \mathbb{R} ; \quad c_{2}=0 ; \quad e_{2}=0 \text {; }
\end{aligned}
$$


and $X_{1}(0)>0, X_{2}(0)=0$ see $(2),(3)$ and Figure 1. The Malthusian model can describe the increase and decrease of a population well, particularly in the initial period of the growth.

\subsection{Logistic growth (Verhulst Model)}

Pierre-François Verhulst (1804-1849) was a Belgian mathematician who generalized the Malthusian model by allowing for the fact that populations encounter internal competition as they grow within a closed environment, and this competition has a tendency to clog the rate of growth (see Figure 2/a). His idea says that while the population continues to grow as time goes on, the rate at which it does this growth gets smaller

$$
\dot{p}(t)=u p(t)-v p^{2}(t)
$$

where $p(t)$ represents the population's size at time $t$ and $u, v \in \mathbb{R}$.

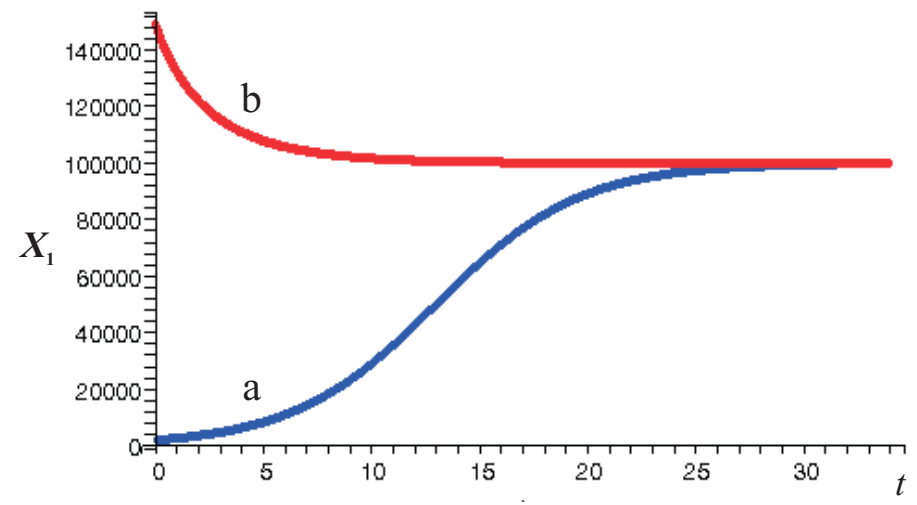

Figure 2. A typical curve of logistic growth. Case a: $b_{1}=0.3 ; a_{11}=$ $3 \cdot 10^{-6} ; X_{1}(0)=2.0 \cdot 10^{3} ; X_{2}(0)=0$. Case b: $b_{1}=0.3 ; a_{11}=3 \cdot 10^{-6}$; $X_{1}(0)=1.5 \cdot 10^{5} ; X_{2}(0)=0$.

This is a slightly more realistic approach than that of Malthus, whose idea actually predicts that populations will grow exponentially, and without termination - a prospect that defies physical limitations. (Malthus was aware that this kind of growth could not continue, so he was really frightened of the whole thing as he looked forward to overpopulation and global famine.) 


$$
\text { "geda" — 2008/8/1 — 11:20 — page } 5-\# 5
$$

When we apply the following values of coefficients and initial values in the proposed equations (1), we can transform our general model into a similar form

$$
\dot{X}_{1}(t)=\left(b_{1}-a_{11} X_{1}(t)\right) X_{1}(t) .
$$

where

$$
\begin{aligned}
& b_{1}>0 ; \quad a_{11}>0 ; \quad a_{12}=0 ; \quad c_{1}=0 ; \quad e_{1}=0 ; \\
& b_{2} \in \mathbb{R} ; \quad a_{21} \in \mathbb{R} ; \quad a_{22} \in \mathbb{R} ; \quad c_{2}=0 ; \quad e_{2}=0 ;
\end{aligned}
$$

and $X_{1}(0)>0, X_{2}(0)=0$ see $(5),(4)$ and Figure 2 .

Verhulst's Model can handle not only the size of population at time $t$, but also the competition of the members of the population and that how many members of the population can support the environment.

The logistic growth equation produces a sigmoidal curve when $b_{1}-a_{11} X_{1}(0)>0$ (see Figure 2/a.). The growth of population is slow at first, then accelerates, and finally slows as population size becomes big enough. Various sorts of phenomena can be described by this model, independently of the fields of science (e.g.: ecology, biology, economy, etc.).

\subsection{Combat Models}

Another interesting application of differential equations arises in the analysis of warfare between two opposing forces $\left(X_{1}, X_{2}\right)$. It was first applied by $\mathrm{F}$. W. Lanchester at the time of World War I.

In a combat model, $\dot{X}_{1}(t)$ and $\dot{X}_{2}(t)$ are called the loss rates of the given armies. They consist of the combat loss rates (due to the enemy's attacks) and operation loss rates (due to ordinary attrition not attributable directly to the enemy, examples might be accidents, plane crashes, deaths due to disease, etc.). In a real situation reinforcement or withdrawal can happen. In our model they could be represented by values of $e_{i}\left(e_{i}>0\right.$ : reinforcement; $e_{i}<0$ : withdrawal, but it will be disregarded in the following and we will consider them as 0 ). In the following, we will consider three possible situations.

- The Conventional Combat Model

... in which both armies wage war against each other using conventional methods

$$
\begin{gathered}
\dot{X}_{1}(t)=b_{1} X_{1}(t)+c_{1} X_{2}(t), \\
\dot{X}_{2}(t)=b_{2} X_{2}(t)+c_{2} X_{1}(t) .
\end{gathered}
$$


$\bigoplus$

$$
\text { "geda" — 2008/8/1 - 11:20 — page } 6 \text { - \#6 }
$$

$$
\begin{aligned}
& b_{1}<0 ; \quad a_{11}=0 ; \quad a_{12}=0 ; \quad c_{1}<0 ; \quad e_{1}=0 ; \\
& b_{2}<0 ; \quad a_{21}=0 ; \quad a_{22}=0 ; \quad c_{2}<0 ; \quad e_{2}=0 ;
\end{aligned}
$$

and $\left.X_{1}(0)>0, X_{2}(0)>0\right)$ see $(6)$ and Figure 3.
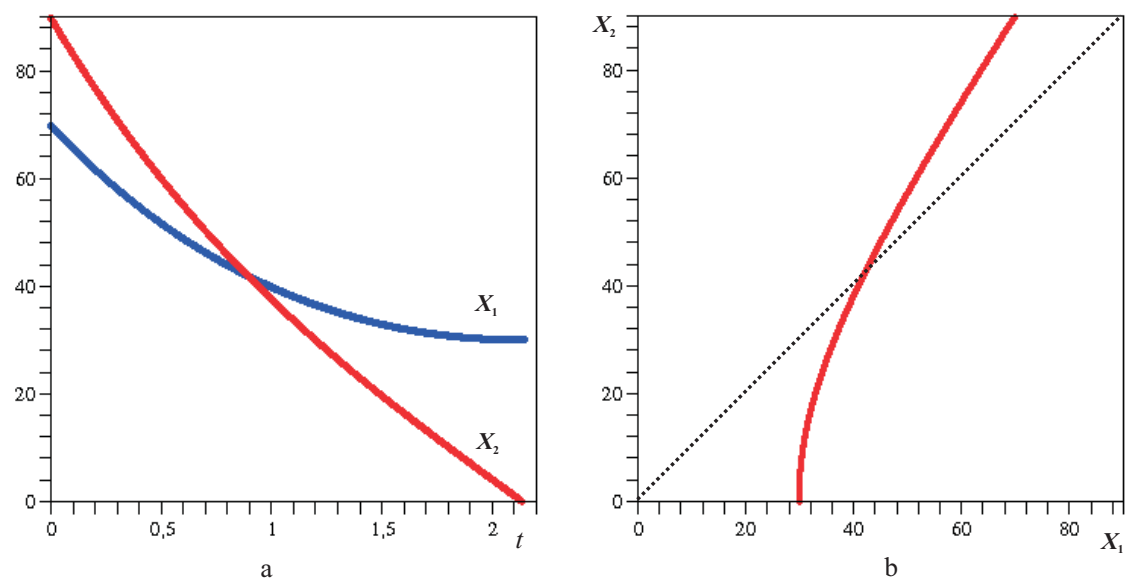

Figure 3. Conventional Combat: $b_{1}=-0.010 ; c_{1}=-0.5 ; b_{2}=-0.007$; $c_{2}=-1.0 ; X_{1}(0)=70 ; X_{2}(0)=90$.
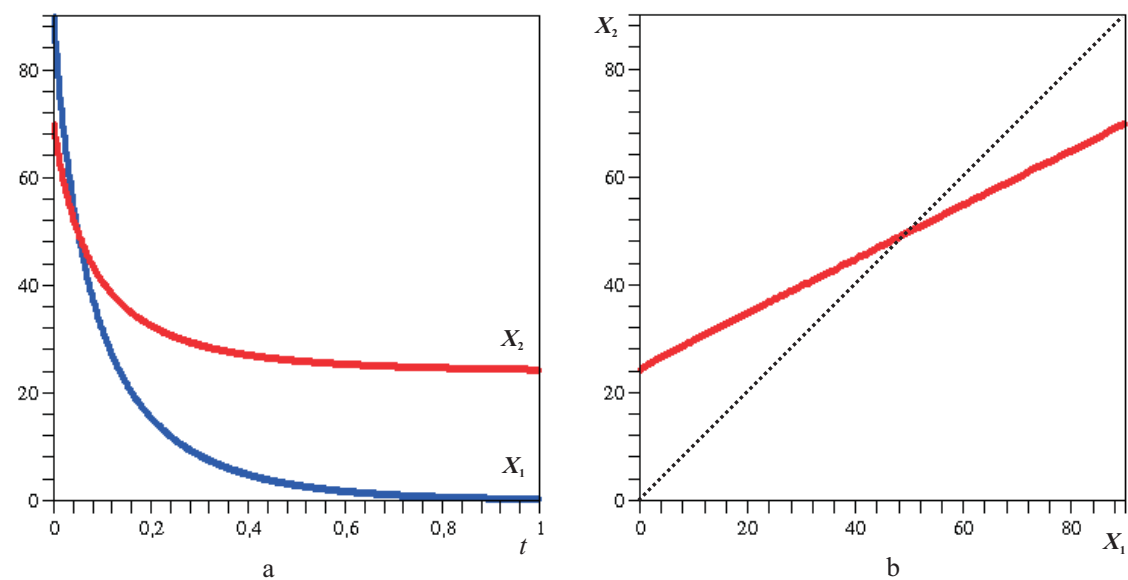

Figure 4. Guerilla Combat: $b_{1}=-0.010 ; a_{12}=0.2 ; b_{2}=-0.003$; $a_{21}=0.1 ; X_{1}(0)=90 ; X_{2}(0)=70$. 
- The Guerilla Combat Model

... in which the two opposing armies wage warfare by using guerilla tactics such as sneak raids on the opposition's base or ambush upon each other.

In this situation we suppose that both of the armies involved are waging guerilla warfare on the other. A possible model for the scenario may be the following system of differential equations

$$
\begin{gathered}
\dot{X}_{1}(t)=b_{1} X_{1}(t)-a_{12} X_{1}(t) X_{2}(t) \\
\dot{X}_{2}(t)=b_{2} X_{2}(t)-a_{21} X_{2}(t) X_{1}(t) . \\
b_{1}<0 ; \quad a_{11}=0 ; \quad a_{12}>0 ; \quad c_{1}=0 ; \quad e_{1}=0 ; \\
b_{2}<0 ; \quad a_{21}>0 ; \quad a_{22}=0 ; \quad c_{2}=0 ; \quad e_{2}=0 ;
\end{gathered}
$$

and $\left.X_{1}(0)>0, X_{2}(0)>0\right)$ see $(7)$ and Figure 4 .
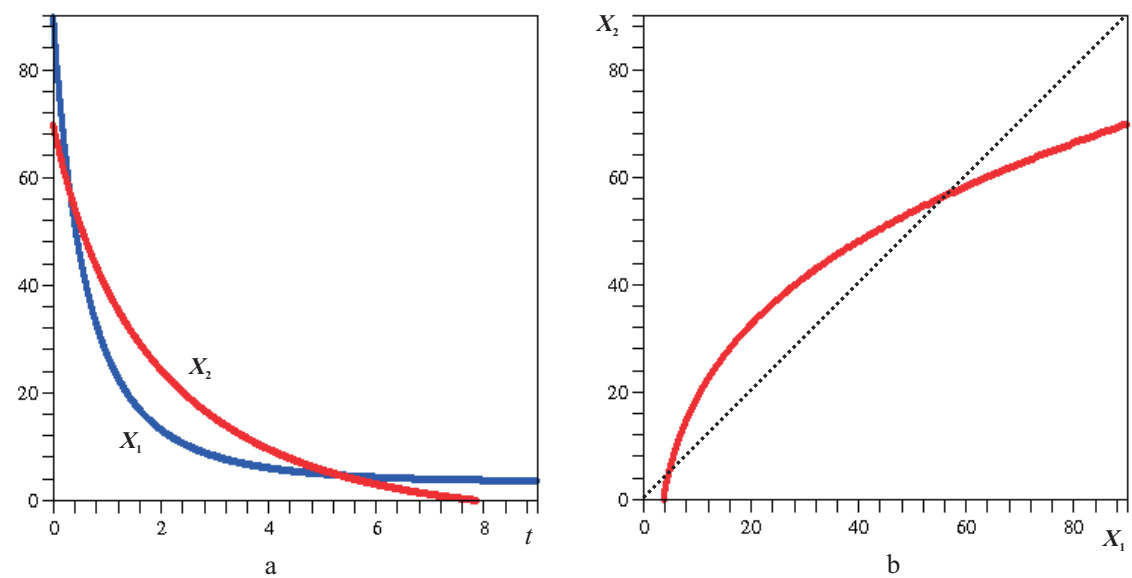

Figure 5. Mixed Combat: $b_{1}=-0.04 ; a_{12}=+0.022 ; b_{2}=-0.30$; $c_{2}=-0.300 ; X_{1}(0)=90 ; X_{2}(0)=70$.

- The Mixed Combat Model

... in which a guerilla force $\left(X_{1}\right)$ is in conflict with an army $\left(X_{2}\right)$ employing conventional warfare methods

$$
\begin{aligned}
& \dot{X}_{1}(t)=b_{1} X_{1}(t)-a_{12} X_{1}(t) X_{2}(t), \\
& \dot{X}_{2}(t)=b_{2} X_{2}(t) \quad+c_{2} X_{1}(t) .
\end{aligned}
$$




$$
\text { "geda" — 2008/8/1 — 11:20 — page } 8 \text { - \#8 }
$$

$$
\begin{aligned}
& b_{1}<0 ; \quad a_{11}=0 ; \quad a_{12}>0 ; \quad c_{1}=0 ; \quad e_{1}=0 ; \\
& b_{2}<0 ; \quad a_{21}=0 ; \quad a_{22}=0 ; \quad c_{2}<0 ; \quad e_{2}=0 ;
\end{aligned}
$$

and $\left.X_{1}(0)>0, X_{2}(0)>0\right)$ see $(8)$ and Figure 5.

\subsection{Prey-Predator model}

One of the most interesting applications of non linear differential equation systems are the prey-predator problems. We should consider an environment containing two interacting populations, a prey population, such as rabbits, and a predator population, such as foxes. Obviously, it is rational to expect that the two populations react in such a way as to influence each other's size.

To describe changes of number of fishes in the Mediterranean Sea an Italian mathematician Vito Volterra proposed an equation system like

$$
\begin{aligned}
& \dot{N}_{1}(t)=\beta_{1} N_{1}(t)-\alpha_{1} N_{1}(t) N_{2}(t), \\
& \dot{N}_{2}(t)=-\beta_{2} N_{2}(t)+\alpha_{2} N_{1}(t) N_{2}(t)
\end{aligned}
$$

based on Umberto D'Ancona's observations in twenty's of last century. (here $\alpha_{i}, \beta_{i} \in \mathbb{R}^{+}, i=1 \ldots 2, N_{1}(t)$ and $N_{2}(t)$ represent the population size of preys and predators at time $t$ respectively.)

According to (9) the change of preys' number $\left(\dot{N}_{1}(t)\right)$ depends on two things. The increase of preys' number is determined only by $N_{1}(t)$, while the reduction of preys' number depends on both $N_{1}(t)$ and $N_{2}(t)$.

To get

$$
\begin{aligned}
& \dot{X}_{1}(t)=\left(b_{1}-a_{11} X_{1}(t)-a_{12} X_{2}(t)\right) X_{1}(t), \\
& \dot{X}_{2}(t)=\left(b_{2}-a_{21} X_{1}(t)-a_{22} X_{2}(t)\right) X_{2}(t)
\end{aligned}
$$

replace the following values into (1) and use the proposed initial values.

$$
\begin{aligned}
& b_{1}>0 ; \quad a_{11} \geq 0 ; \quad a_{12}>0 ; \quad c_{1}=0 ; \quad e_{1}=0 ; \\
& b_{2}<0 ; \quad a_{21}<0 ; \quad a_{22} \geq 0 ; \quad c_{2}=0 ; \quad e_{2}=0 ;
\end{aligned}
$$

and $\left.X_{1}(0) \gg 1, X_{2}(0) \gg 1\right)$ see $(10)$ and Figure 6 .

Using suitable initial values $\left(X_{1}(0) \gg 1, X_{2}(0) \gg 1\right)$ and parameters $\left(a_{11} \geq\right.$ $\left.0, a_{12}>0, a_{22} \geq 0, a_{21}<0, b_{1}>0, b_{2}<0\right)$ we can get the well-known form of predator-prey model

$$
\begin{aligned}
& \dot{X}_{1}(t)=\left(b_{1}-a_{12} X_{2}(t)\right) X_{1}(t), \\
& \dot{X}_{2}(t)=\left(b_{2}-a_{21} X_{1}(t)\right) X_{2}(t)
\end{aligned}
$$

from (1). 


$$
\text { "geda" — 2008/8/1 — 11:20 — page } 9-\# 9
$$
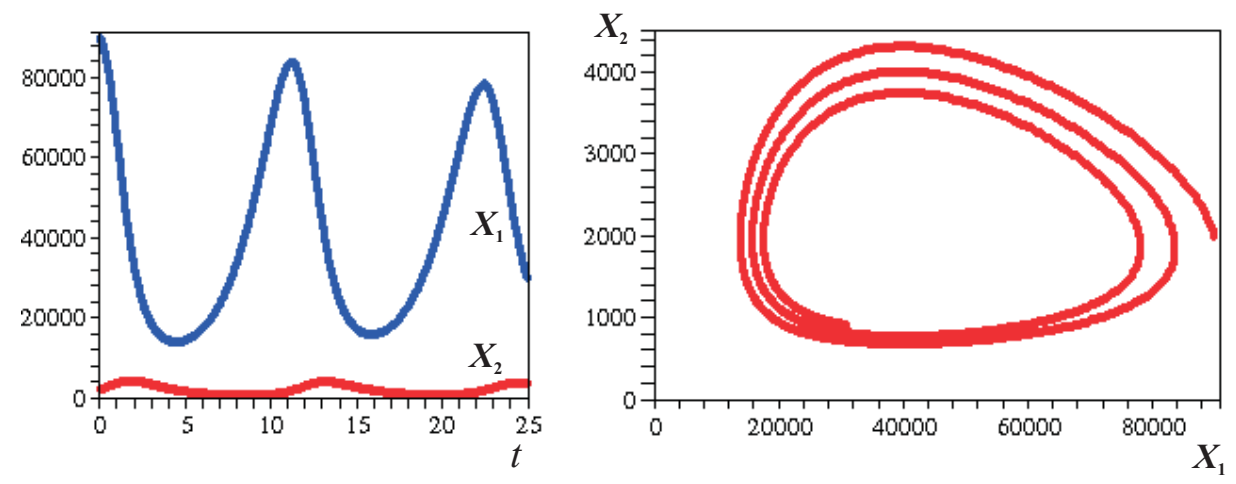

Figure 6. Prey-Predator model: $b_{1}=+0.6 ; a_{11}=+0.5 \cdot 10^{-7}$; $a_{12}=+0.3 \cdot 10^{-4} ; b_{2}=-0.6 ; a_{21}=-1.5 \cdot 10^{-5} ; X_{1}(0)=90000 ;$ $X_{2}(0)=2000$.
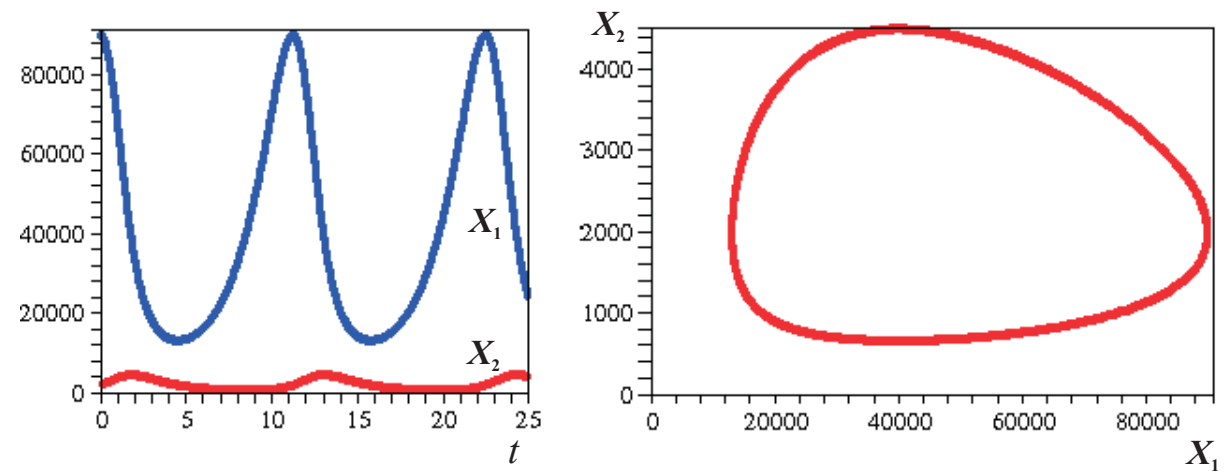

Figure 7. Prey-Predator model: $b_{1}=+0.6 ; a_{12}=+0.3 \cdot 10^{-4}$; $b_{2}=-0.6 ; a_{21}=-1.5 \cdot 10^{-5} ; X_{1}(0)=90000 ; X_{2}(0)=2000$.

\subsection{Oscillation}

Independently of fields of science (electronics, mechanics, structure of materials) the oscillation can be described in a similar way by using

$$
\ddot{X}(t)=-\frac{c}{m} \dot{X}(t)-\omega_{0}^{2} X(t)
$$

differential equation. That is why in the following we study the mechanical oscillation.

If the spring is attached to an external force, the differential equation becomes nonhomogeneous. (Where $c>0$ (damping constant) characterizes the friction, $m$ 


$$
\text { "geda" — 2008/8/1 — 11:20 — page } 10-\# 10
$$

is the mass of moving object, $\omega_{0}$ is the characteristic angular frequency, and $X(t)$ is the deflection of object from repose at $t$.)

The (12) equation can be transformed into a system of differential equations

$$
\begin{aligned}
\dot{X}_{1}(t) & =X_{2}(t), \\
\dot{X}_{2}(t) & =-\frac{c}{m} X_{2}(t)-\omega_{0}^{2} X_{1}(t) .
\end{aligned}
$$

- Harmonic oscillator

or

$$
\begin{aligned}
& b_{1}=0 ; \quad a_{11}=0 ; \quad a_{12}=0 ; \quad c_{1}=1 ; \quad e_{1}=0 ; \\
& b_{2}=0 ; \quad a_{21}=0 ; \quad a_{22}=0 ; \quad c_{2}=-\omega_{0}^{2} ; \quad e_{2}=0 ;
\end{aligned}
$$

$$
\begin{aligned}
& b_{1}=0 ; \quad a_{11}=0 ; \quad a_{12}=0 ; \quad c_{1}=\omega_{0} ; \quad e_{1}=0 ; \\
& b_{2}=0 ; \quad a_{21}=0 ; \quad a_{22}=0 ; \quad c_{2}=-\omega_{0} ; \quad e_{2}=0 ;
\end{aligned}
$$

and $X_{1}(0) \neq 0$ or $\left.X_{2}(0) \neq 0\right)$ see $(12),(13)$

$$
\begin{aligned}
& \dot{X}_{1}(t)=c_{1} X_{2}(t) \\
& \dot{X}_{2}(t)=c_{2} X_{1}(t)
\end{aligned}
$$

and Figure 8.
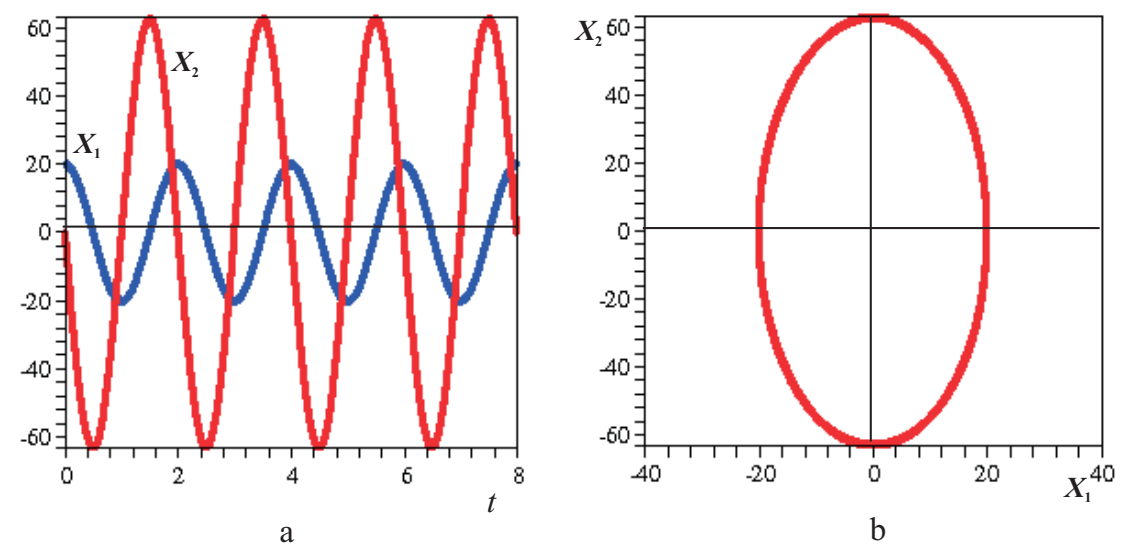

Figure 8. Harmonic oscillator: $c_{1}=1 ; c_{2}=\pi^{2} ; X_{1}(0)=20 ; X_{2}(0)=0$. 


$$
\text { "geda" — 2008/8/1 — 11:20 — page } 11 \text { — \#11 }
$$

- Free dumped oscillator

When the surroundings offer resistance to the spring, damped motion results.

$$
\begin{aligned}
& b_{1}=0 ; \quad a_{11}=0 ; \quad a_{12}=0 ; \quad c_{1}=1 ; \quad e_{1}=0 ; \\
& b_{2}=-\frac{c}{m} ; \quad a_{21}=0 ; \quad a_{22}=0 ; \quad c_{2}=-\omega_{0}^{2} ; \quad e_{2}=0 ;
\end{aligned}
$$

and $X_{1}(0) \neq 0$ or $\left.X_{2}(0) \neq 0\right)$ see $(12),(13)$,

$$
\begin{aligned}
& \dot{X}_{1}(t)=\quad c_{1} X_{2}(t), \\
& \dot{X}_{2}(t)=b_{2} X_{2}(t)+c_{2} X_{1}(t),
\end{aligned}
$$

and Figure 9 .

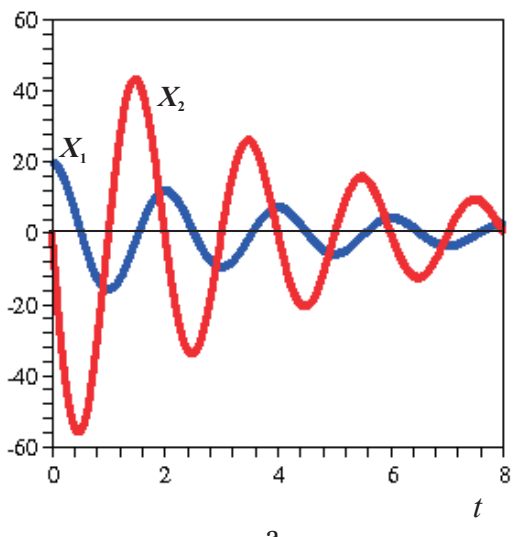

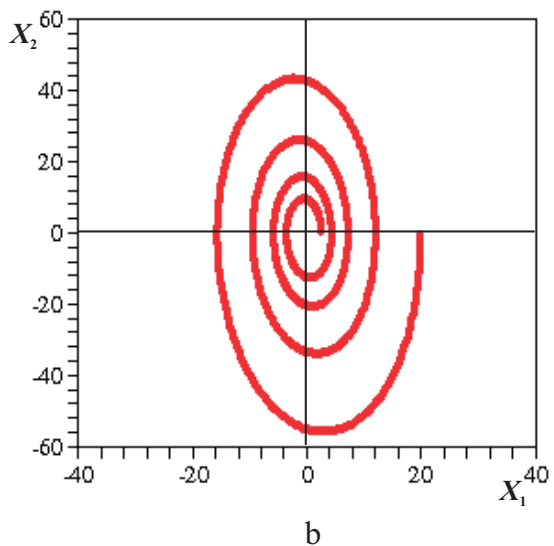

Figure 9. Free dumped oscillator (based on (1), made by Maple): $c_{1}=1 ; b_{2}=-0,5 ; c_{2}=\pi^{2} ; X_{1}(0)=20 ; X_{2}(0)=0$.

\section{Conclusion}

As we can see, after giving the equations the modelled system is defined by the initial conditions and the coefficients. The possible values of this (integer or fraction, positive or negative ...), is defined by the feature of the modelled system, so by the proper choice of above values we can give the models of different, well-known systems. 
The state of the system at time $t$ is characterised by the value $X_{1}(t)$ and $X_{2}(t)$. By selecting the values of $a_{i j}, b_{i}, c_{i}$, we can take into consideration the influence of the present state of the system on its future state. The effects of outer factors can be described by $e_{i}$.

For example in case of a reproduction model the number of the modelled population may change by incoming entities (settling, immigration) or on the contrary the population may decrease due to on outer factor. The situation is the same in case of reproduction of endangered species in artificial condition so that they can be taken back to their natural surroundings. The devices of numerical mathematics facilitate the unified treating of the model mentioned above.

We do not deny the importance of the mathematical background standing behind the topic, on the contrary, we would like to emphasize it, as the approaching methods can not exist without them. We think that the spread of the computers gives a chance to a practical, concept-based approach. We hope all this will provide appropriate experience for those are interested in to study this topic in an exact way.

Depending on the level of education this can be realised by the use of some mathematical auxiliary programme but easily algorythmised approaching methods can also be applied provided somebody has certain programming knowledge. The further advantage of the equations is that they can be interpreted if somebody is aware of direct proportionality so they are suitable for introducing mathematical models at an early stage of education.

\section{References}

[1] M. Arató, A Famous Nonlinear Stocshastic Equation (Lotka-Volterra Model with Diffusion), Mathematical and Computer Modelling 38 (2003), 709-726.

[2] P. W. Atkins, Physical Chemistry I-III., Oxford Univesity Press, Oxford, 1990.

[3] Gy. Bazsa, Nem lineáris dinamika és egzotikus kinetikai jelenségek kémiai rendszerekben, egyetemi jegyzet, 1992.

[4] R. L. Borrelli, C. S. Coleman, Differential Equations: A Modeling Perspective, $2^{\text {nd }}$ edition, Wiley, New York, 2004.

[5] G. Geda, Investigation of Stability of Nonlinear Differential Equations with Stochastic Methods, XXVI. Seminar on Stability Problems for Stochastic Models, Szováta, 2006.

[6] G. Geda, Investigation of Stochastic Models of Some Periodic Phenomena, $7^{\text {th }}$ International Conference on Applied Informatics, Eger, 2007. 


$$
\text { "geda" — 2008/8/1 — 11:20 — page } 13 \text { — \#13 }
$$

[7] L. Hatvani, L. Pintér, Differenciálegyenletes modellek a középiskolában, POLIGON, 1997.

[8] K. K. Ponomarjow, Differenciálegyenletek felállítása és megoldása, Tankönyvkiadó, Budapest, 1981.

[9] M. Rontó, P. Rajsz, Differenciálegyenletek müszakiaknak, Miskolci Egyetemi Kiadó, 2004.

[10] J. Tóth, L. P. Simon, Differenciálegyenletek, Bevezetés az elméletbe és az alkalmazásokba, TYPOTEX Kiadó, 2005.

GÁBOR GEDA

ESZTERHÁZY KÁROLY COLLEGE

DEPARTMENT OF COMPUTER SCIENCE

EGER

HUNGARY

E-mail: gedag@aries.ektf.hu

(Received May, 2007) 